\title{
Palpable Masses Group Identifier
}

National Cancer Institute

\section{Source}

National Cancer Institute. Palpable Masses Group Identifier. NCI Thesaurus. Code

C119909.

A character or string that represents a palpable masses group. 